26(5), 807-819

\title{
Exploratory Data Analysis for Korean Stock Data with Recurrence Plots
}

\author{
Dae-Heung $\operatorname{Jang}^{a, 1}$ \\ ${ }^{a}$ Department of Statistics, Pukyong National University \\ (Received August 22, 2013; Revised September 27, 2013; Accepted September 30, 2013)
}

\begin{abstract}
A recurrence plot can be used as a graphical exploratory data analysis tool before confirmatory time series analysis. With the recurrence plot, we can obtain the structural pattern of the time series and recognize the structural change points in a time series at a glance. Korean stock data shows the usefulness of the recurrence plot as a graphical exploratory data analysis tool for time series data.
\end{abstract}

Keywords: KOSPI index, recurrence plot, stationarity.

\section{1. 서론}

모형에 기반을 둔 시계열 자료에 대한 전통적인 통계적 분석으로서 자기회귀적분이동평균모형 (ARIMA 모형)이 있으며 시간의 경과에 따른 분산의 변동을 고려한 통계적 분석 모형으로서 자기회귀조건부이분 산성모형 $(\mathrm{ARCH}$ 모형), 일반화자기회귀조건부이분산성모형 $(\mathrm{GARCH}$ 모형 $)$, 이 들 모형들의 확장모형 등을 주로 사용된다(가장 최근의 국내 연구 예들로 Hwang과 Shin (2013), Kim과 Kim (2013), Lee와 Noh (2013), Oh와 Kim (2013), Park 등 (2013) 등이 있다.). 탐색적 자료분석에서는 자료를 모형에 바 로 적합시키기 보다는 자료를 있는 그대로 보려는 데 주안점을 둔다. 시계열 자료에 대한 탐색적 자료분 석방법으로서 단순평활기와 복합평활기 $(4253 \mathrm{H}, 3 \mathrm{RSSH}, 3 \mathrm{RS} 3 \mathrm{R}$ 등)를 사용한다. 이 평활기들은 잡음 이 섞인 시계열 자료에서 신호를 매끄럽게 분리하기 위한 탐색적 방법이다.

Eckmann 등 (1987)은 동적 시스템의 위상공간(phase space) 상태의 재현을 시각화하는 재현그 림(recurrence plot)을 제안하였다. 재현그림은 이론물리학에서 비선형 시계열이나 혼돈 시스템의 패턴 과 성질을 밝히기 위하여 고안되었다. Marwan 등 (2007)은 재현그림에 대한 리뷰 페이퍼를 잘 정리하 여 발표하였다.

이 재현그림은 최근에 다양한 학문분야(경제/경영학, 전산학, 음향학, 생물학, 지질학, 의학 등)에 서 사용하고 있다. 국내 연구 중 통계학/전산학분야에서 난수의 임의성을 평가하기 탐색적 그림도 구로서 재현그림을 적용한 예로서 Jang (2009)이 있다. 경제/경영학 분야에서 Belaire-Franch 등 (2002)이 재현그림을 통한 주식 자료의 분석을 시도하였고 재현그림을 통한 주식시장에 대한 분석으로

This work was supported by the Pukyong National University Research Fund in 2010(PK-2010-037).

${ }^{1}$ Professor, Department of Statistics, Pukyong National University, 45 Yongso-Ro, Nam-Gu, Pusan 608-707, Korea. E-mail: dhjang@pknu.ac.kr 
서는 Guhathakurta 등 (2010)이 내생 주식시장 붕괴와 외생 주식시장 붕괴를 구별하기 위한 수단으로 서 재현그림과 재현수량화분석(recurrence quantification analysis; RQA)을 사용할 것을 제안하였다. Chen (2011)은 재현그림과 재현수량화분석을 사용하여 대만의 실업률 데이터에 대한 분석을 행하였다. Addo 등 (2013)은 재정위기를 탐지하기 위한 수단으로서 재현그림을 제시하였다.

우리는 시계열 자료값의 차이에 관심을 가질 때가 종종 있다. 예로 주가분석에서 주가의 차이가 중요한 경우가 있다. 이 때 재현그림이 시계열 자료에 대한 탐색적 그림도구로서 유용하게 쓰일 수 있다. 이러 한 재현 그림을 구현하는 데 있어서 통계모형에 대한 가정이 필요 없으므로 그래픽 탐색적 자료분석 도 구로서 유용한 수단이 될 수 있다.

본 논문에서 사용한 KOSPI지수(Korean composite stock price index) 데이터는 1995년 5월 2일부 터 2013년 8월 6일까지 17여년간 일별 KOSPI지수 데이터로서 총 데이터 개수는 4,690개이다. 본 논 문에서는 KOSPI지수 데이터를 대상으로 시계열 자료값과 자료값의 차이에 촛점을 맞추어 재현그림을 작성하고 시계열 데이터에 대한 패턴을 살펴보았다. 2절에서는 재현그림에 대한 간단한 소개와 아울러 $\mathrm{KOSPI}$ 지수 데이터 및 차분 데이터의 정상성에 대하여 언급하였다. 3 절에서는 KOSPI지수 데이터에 대한 재현그림을 통하여 이 재현그림이 시계열 데이터에 대한 패턴을 볼 수 있는 그래픽 탐색적 자료분 석 도구로서 유용한 수단이 될 수 있음을 보였고 4절에서는 우리나라 상장기업의 대표적 주식인 삼성전 자 주가 데이터에 대한 재현그림에 대하여 언급하고 KOSPI지수 데이터에 대한 재현그림과 비교하였다. 5절에서 결론으로 마무리하였다.

\section{2. 재현그림}

시계열자료 $u_{t}\left(t=1,2, \ldots, N_{0}\right)$ 가 주어졌을 때 위상공간은 테이켄스정리에 의하여 다음과 같이 재구성 될 수 있다.

$$
\mathbf{x}_{i}=\left(u_{i}, u_{i+\tau}, \ldots, u_{i+\tau(m-1)}\right),
$$

여기서 $\mathbf{x}_{i}, i=1,2, \ldots, N$ 은 위상공간 궤도(trajectory)이고, $N$ 은 위상공간 상태의 개수, $u_{i}$ 는 시계열 이고 $m$ 은 매립차원(embedding dimension)이며 $\tau$ 는 시간지연(time delay)이고 $N_{0}=N+\tau(m-1)$ 이 다. 재현그림을 통하여 우리는 $m$-차원 위상공간 궤도를 2 차원으로 표시하여 탐구할 수 있다. (분계)재 현그림((thresholded) recurrence plot)은 다음과 같은 재현행렬로 표현할 수 있다.

$$
R_{i, j}(\epsilon)=\Theta\left(\epsilon-\left\|\mathbf{x}_{i}-\mathbf{x}_{j}\right\|\right),
$$

여기서 $\mathbf{x}_{i}, \mathbf{x}_{j} \in R^{m}, i, j=1,2, \ldots, N$ 이고, $\epsilon$ 은 분계점(threshold) 거리, $\|\cdot\|$ 은 노름, $\Theta$ 는 헤비사이 드(Heaviside) 함수이다. 헤비사이드(Heaviside) 함수 $\Theta(x)$ 는 $x<0$ 일 때는 0 이고 $x \geq 0$ 일 때는 1 이 되는 함수이다. 두 개의 위상공간 $\mathbf{x}_{i}$ 와 $\mathbf{x}_{j}$ 의 거리가 $\epsilon$ 보다 작거나 같으면 위상공간 궤도가 같은 위치 에 있다고 보아 $\mathbf{R}_{i, j}(\epsilon)=1$ 이 되어 정사각형 모양의 재현그림에서 $x$ 축에서의 $i$-번째 시점과 $y$ 축에서의 $j$-번째 시점에 해당하는 위치에 점으로 나타나게 된다. 모든 $i, j=1,2, \ldots, N$ 에 대하여 $\mathbf{R}_{i, j}(\epsilon)=1$ 일 때만 $(i, j)$ 위치에 점을 찍으면 재현그림이 완성된다.

재현그림에 나타나는 점들의 패턴을 살펴봄으로써 시계열 자료값의 재현성을 탐색적으로 검토하여 볼 수 있다. 주식분석의 예에서 재현그림 상 두 시점에서 점이 나타난다면 이 두 시점에서의 주가가 거의 유사하다는 것을 알 수 있게 되고 재현 그림상의 집락이나 패턴을 통하여 어떤 시점들의 그룹이 어떤 시 점들의 그룹과 연관성을 갖는 지를 탐색적으로 알 수 있게 된다.

재현그림에서 중요한 모수가 분계점 $\epsilon$ 의 값이다. $\epsilon$ 이 너무 작으면 정사각형의 재현그림에서 점들을 거 의 볼 수 없게 되어 빈 공간에 가까운 재현그림이 되고, $\epsilon$ 이 너무 크면 재현그림에서 거의 모든 점들 

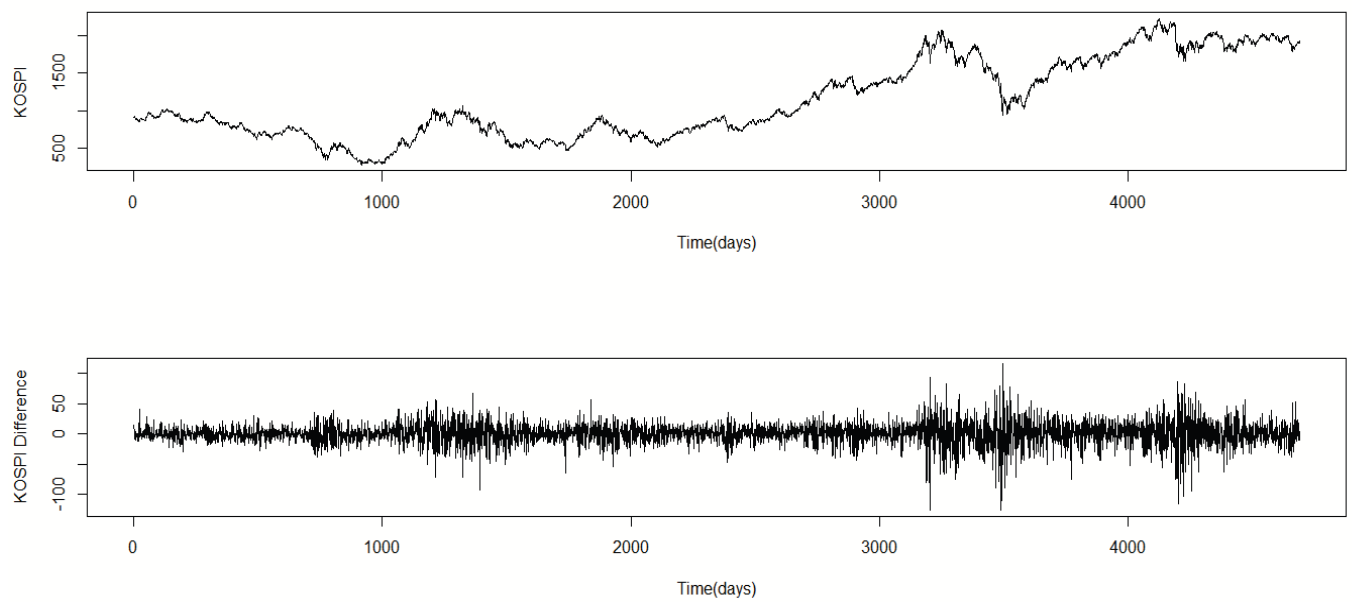

Figure 2.1. KOSPI data and first differenced KOSPI data

이 다른 점들의 이웃이 되어 정사각형의 공간을 모든 점들이 채워 거의 까맣게 되는 재현그림이 된다. Mindlin과 Gilmore (1992), Zbilut와 Webber Jr. (1992), Matassini 등 (2002), Thiel 등 (2002), Zbilut 등 (2002)이 분계점 $\epsilon$ 의 값을 선택하는 방법들에 대하여 연구하였다.

재현그림과 더불어 우리는 비분계재현그림(unthresholded recurrence plot)을 그릴 수 있는 데 비분계 그림은 다음과 같은 거리행렬로 표현할 수 있다.

$$
D_{i, j}=\left\|\mathbf{x}_{i}-\mathbf{x}_{j}\right\|,
$$

여기서 $\mathbf{x}_{i}, \mathbf{x}_{j} \in R^{m}, i, j=1,2, \ldots, N$ 이고, $\|\cdot\|$ 은 노름이다.

어떻게 재현그림을 시계열 자료에 대한 탐색적 그림도구로서 쓸 수 있는 지를 우리나라 KOSPI지수 데 이터를 이용하여 살펴볼 수 있다. Iwanski와 Bradley (1998)는 저차원 동적 시스템에서 재현그림 통 계량들(DET, LAM, $L_{\max }, V_{\max }, L, \mathrm{TT}$ 등)이 매립차원 $m$ 에 불변(invariant)함을 보였다. 이런 이유와 더불어 탐색적 자료분석의 성격상 매립차원 $m$ 과 시간지연 $\tau$ 를 고려할 필요가 없이 원 시계열 자료 자체 를 이용하면 된다. 즉 $m=1$ 로 놓으면 된다. 또한 노름은 유클리드 거리를 이용하기로 하고 모든 예제 에서 특별한 언급이 없는 한 $\epsilon$ 으로 시계열 자료에 대한 범위의 $1 / 10$ 배 또는 $1 / 20$ 배를 이용하기로 한다. 재현그림을 그리기 위한 소프트웨어로서 Visual Recurrence Analysis와 CRP를 사용하였다.

Figure 2.1은 KOSPI지수 데이터와 KOSPI지수 데이터에 대한 차분 데이터를 나타낸다. 1차 차분을 통하여 평균이 일정하여 졌음을 알 수 있다. Figure 2.2 는 차분 데이터에 대한 바이올린그림, 상자그 림 그리고 정규확률플롯이다. 특이값들이 다수 존재함을 알 수 있다. Shapiro-Wilk 검정을 행하니 정 규성으로부터 많이 벗어남을 알 수 있다 $(p$-값 $<0.0001)$. 즉 정규분포보다 꼬리가 매우 두꺼움 (왜도가 -0.4742 , 첨도가 7.7138 임)을 알 수 있어 변동성이 큼을 알 수 있다.

Figure 2.3은 KOSPI지수 데이터에 대한 자기상관함수(ACF)와 편자기상관함수(PACF) 그림을 나타 낸다. $\mathrm{ACF}$ 를 보면 값이 아주 서서히 줄지만 그 값이 1 에 가깝고 $\mathrm{PACF}$ 에서는 $\mathrm{lag}=1$ 에서 값이 1 에 가깝고 이 후 급격히 준다. KOSPI지수 데이터가 비정상 시계열임을 알 수 있다. Figure 2.4는 차분 데 이터에 대한 $\mathrm{ACF}$ 와 $\mathrm{PACF}$ 그림을 나타낸다. $\mathrm{ACF}$ 를 보면 주가 데이터의 경우와 달리 값이 급격히 줄 어있음을 알 수 있고 $\mathrm{PACF}$ 에서도 값이 매우 작음을 알 수 있다. 차분 데이터는 정상 시계열임을 알 수 

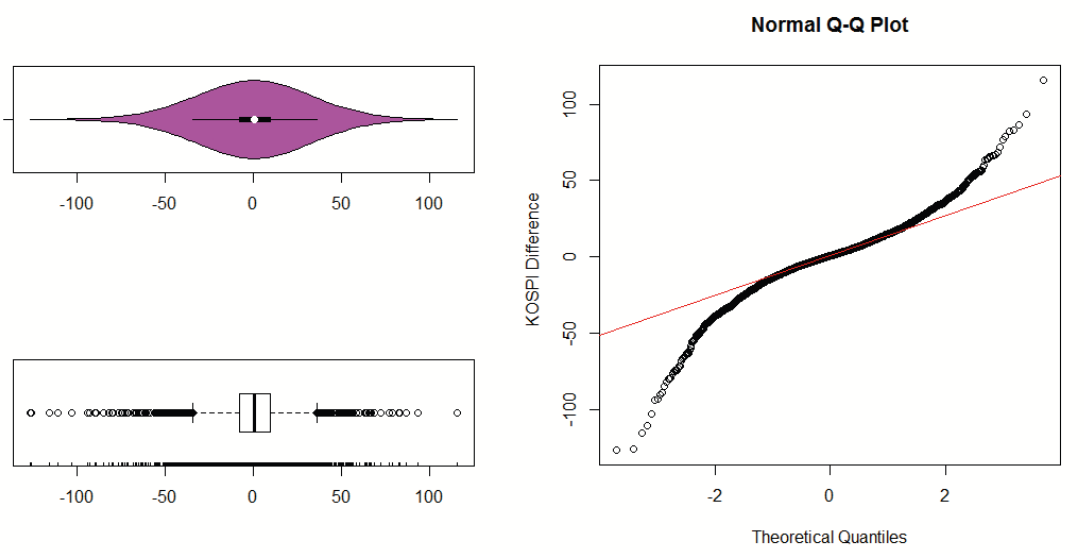

Figure 2.2. Violin plot, box plot, and normal probability plot for first differenced KOSPI data
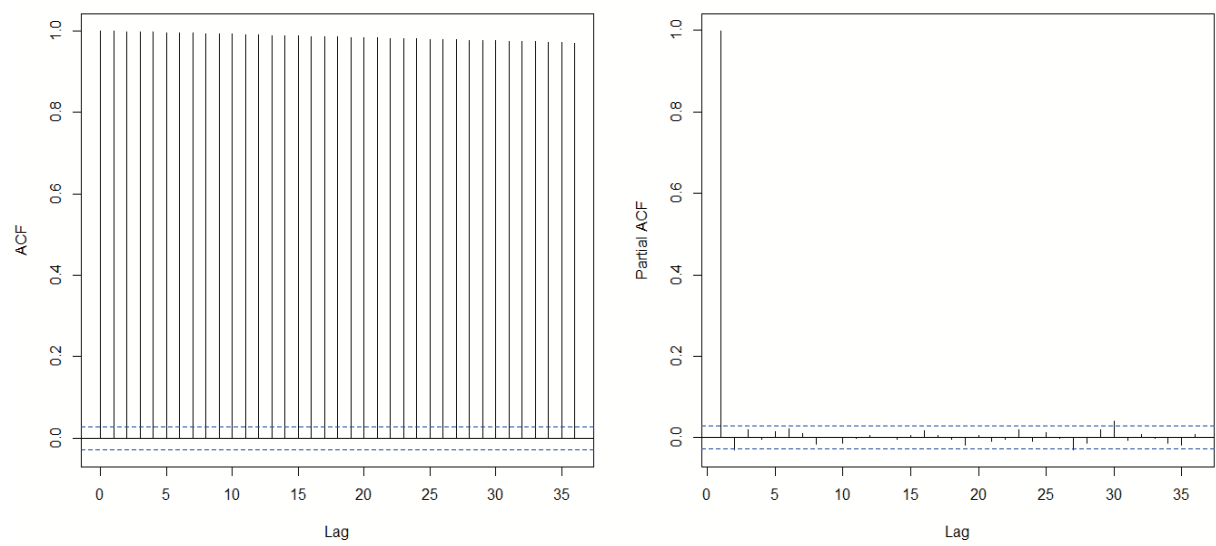

Figure 2.3. $\mathrm{ACF}$ and $\mathrm{PACF}$ for KOSPI data
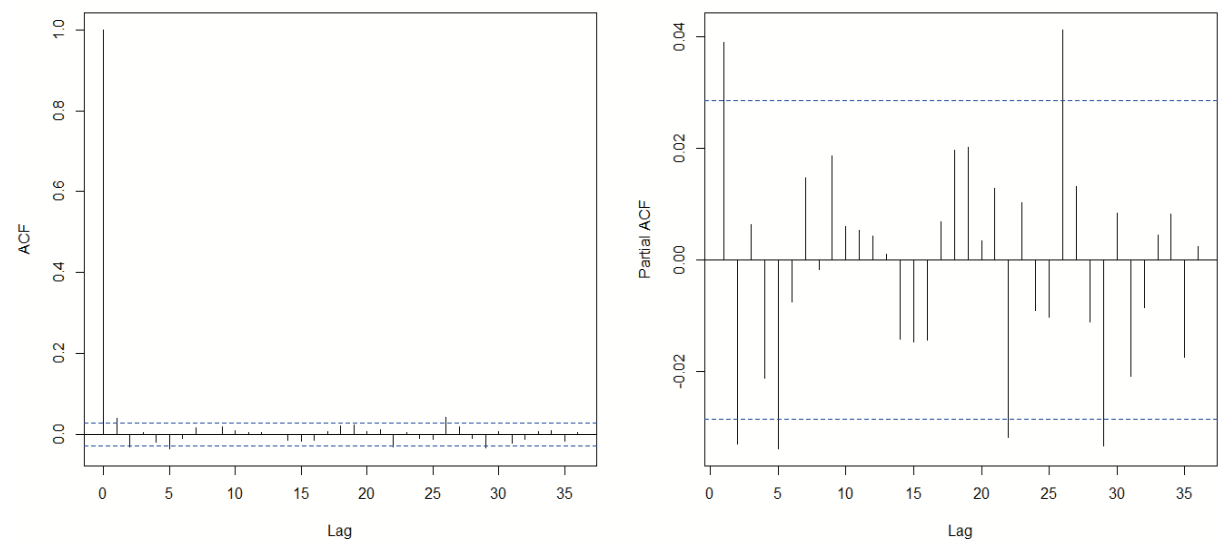

Figure 2.4. $\mathrm{ACF}$ and PACF for first differenced KOSPI data 

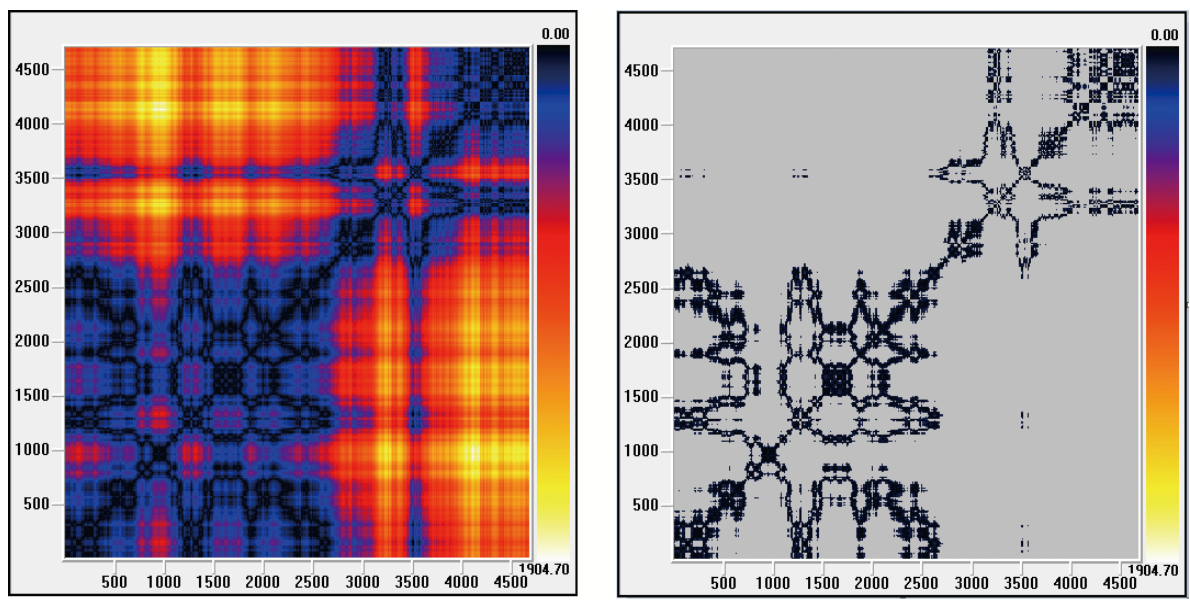

Figure 3.1. Unthresholded recurrence plot and (thresholded) recurrence plot for KOSPI data

있다.

시계열의 정상성 판단을 위하여 $\mathrm{ADF}$ (augmented Dickey-Fuller) 검정을 행하니 KOSPI지수 데이터에 대한 Dickey-Fuller 검정통계량은 $0.3483, p$-값은 0.7274 로서 KOSPI 지수 데이터가 비정상 시계열임 을 알 수 있었고 차분 데이터에 대한 Dickey-Fuller 검정통계량은 $-48.0317, p$-값은 0.01 로서 차분 데이 터가 정상 시계열임을 알 수 있었다.

\section{KOSPI 지수 데이터에 대한 재현그림을 통한 탐색적 자료분석}

KOSPI지수 데이터에 대하여 비분계재현그림과 (분계)재현그림을 그려보면 Figure 3.1과 같다. 비분 계재현그림에서 칼라색이 골고루 퍼져 있지 않고 다수의 특정 색깔들의 클러스터를 확인할 수 있어 비정상 시계열임을 확인할 수 있다. (분계)재현그림에서 점들이 골고루 퍼져 있지 않고, 특히 좌상, 우하 구석의 빈 공간 및 중간 중간의 빈 공간으로 인하여 비정상 시계열임을 확인할 수 있다. 또한 Chen (2011)이 제시했던 P-C-L-C 싸이클과 유사한 싸이클을 확인할 수 있고 이 싸이클을 통하여 탐 색적으로 시계열 데이터의 구조 변화점을 한 눈에 확인할 수 있게 된다. P-C-L-C 싸이클이란 시계열 처음에서 $\mathrm{P}$ (periodic zone)이 나타나고 다음에 차례로 $\mathrm{C}$ (chaotic-looking zone), $\mathrm{L}$ (laminar patch), $\mathrm{C}$ (chaotic-looking zone)가 뒤따른다는 것을 말한다. P는 KOSPI지수의 주기성이 나타나는 영역, $\mathrm{C}$ 는 KOSPI지수의 급락 또는 급등이 나타나는 영역, 그리고 L은 KOSPI지수의 변동이 심하지 않은 안정된 영역이다. (분계)재현그림에서 PL-C 싸이클이 반복해서 나타난다. 여기서 PL이란 P(periodic zone) 와 L(laminar patch)이 혼재되어 있는 영역을 가리킨다. 특이한 것은 나중에 언급할 구조변화점 위치 $t=3470$ (2008년 미국 서브프라임사태로 촉발된 금융위기) 이후 나타나는 골짜기 구간(극소점)에 해당 하는 주가가 앞선 날짜 상당 부분에서 재현되고 있다는 것이다.

시계열 데이터의 구조 변화점을 한 눈에 확인하기 위하여 재현수량화분석을 이용할 수 있다. 재현 그림에서 점들의 미세한 구조는 다음 Table 3.1 과 같은 재현수량화분석 측도값들을 사용하여 복잡 성(complexity)을 측정할 수 있다.

Figure 3.2 는 KOSPI지수 데이터에 대하여 창(window)의 크기를 100 으로 하여 창을 1 에서 시작하여 1 씩 증가하여 움직이며 구한 각 종 재현수량화분석을 위한 측도값들을 그린 그림들이다(대각선 최소길 
Table 3.1. Measures in recurrence quantification analysis

\begin{tabular}{|c|c|c|c|}
\hline Measures & Names & Contents & Numeric Equations \\
\hline Variance & Variance & variance & \\
\hline $\mathrm{RR}$ & Recurrence Rate & the density of recurrence points & $\frac{1}{N} \sum_{i, j=1}^{N} R_{i, j}(\epsilon)$ \\
\hline DET & Determinism & $\begin{array}{l}\text { the ratio of recurrence points } \\
\text { that form diagonal structures } \\
\text { (of at least length } l_{\min } \text { ) } \\
\text { to all recurrence points }\end{array}$ & $\begin{array}{l}\frac{\sum_{l=l_{\min }}^{N} l P(l)}{\sum_{l=1}^{N} l P(l)}, \text { where } \\
P(l) \text { is the density function } \\
\text { of diagonal lines of length } l\end{array}$ \\
\hline$L$ & Length & the average diagonal line length & $\frac{\sum_{l=l_{\min }}^{N} l P(l)}{\sum_{l=l_{\min }}^{N} P(l)}$ \\
\hline ENTR & Entropy & $\begin{array}{l}\text { Shannon Entropy of } p(l) \text { to find } \\
\text { a diagonal line of exactly length } l\end{array}$ & $\begin{array}{c}-\sum_{l=l_{\min }}^{N} p(l) \ln p(l), \text { where } \\
p(l)=P(l) / N_{l}, N_{l}=\sum_{l \geq l_{\text {min }}} P(l)\end{array}$ \\
\hline LAM & Laminarity & $\begin{array}{l}\text { the ratio of recurrence points } \\
\text { that form vertical structures } \\
\text { (of at least length } v_{\min } \text { ) } \\
\text { to all recurrence points }\end{array}$ & $\begin{array}{c}\frac{\sum_{v=v_{\min }}^{N} v P(v)}{\sum_{v=1}^{N} v P(v)}, \text { where } \\
P(v) \text { is is the density function } \\
\text { of vertical lines of length } l\end{array}$ \\
\hline $\mathrm{TT}$ & Trapping Time & the average vertical line length & $\frac{\sum_{v=v_{\min }}^{N} v P(v)}{\sum_{v=v_{\min }}^{N} P(v)}$ \\
\hline RTE & $\begin{array}{l}\text { Recurrence Time } \\
\text { Entropy }\end{array}$ & $\begin{array}{l}\text { the measure for determining } \\
\text { the periodicity }\end{array}$ & $\begin{array}{c}-\left(\ln T_{\max }\right)^{-1} \sum_{t=1}^{T_{\max }} P(t) \ln P(t) \\
\text { where } P(t) \text { is the recurrence } \\
\text { period density function and } \\
T_{\max } \text { is the largest recurrence value }\end{array}$ \\
\hline$T_{2}$ & $\begin{array}{l}\text { Recurrence Times } \\
\text { of Second Type }\end{array}$ & $\begin{array}{l}\text { recurrence times } \\
\text { of second type }\end{array}$ & $\begin{array}{c}T_{j}^{2}=\left|\left\{i, j: \mathbf{x}_{i}, \mathbf{x}_{j} \in R_{i} ; \mathbf{x}_{j-1} \notin R_{i}\right\}\right| \\
\text { where } R_{i} \text { are the recurrence points } \\
\text { which belong to the state } \mathbf{x}_{i}\end{array}$ \\
\hline
\end{tabular}

이 $l_{\min }$ 과 수직선 최소길이 $v_{\min }$ 는 2 로 하였음.). $\mathrm{PL}-\mathrm{C}$ 싸이클을 확인할 수 있고 이 싸이클을 통하여 탐색적으로 시계열 데이터의 구조 변화점을 한 눈에 확인할 수 있다. 시계열 전체를 크게 보면 4 개의 구 간(1, 2, 3, 4구간)으로 나눌 수 있다. 1 구간은 다시 3 개의 소구간(1-1, 1-2, 1-3소구간)으로 나눌 수 있 다. 6 개 구간을 구분하는 구조변화점 위치는 $t=760,1320,3170,3470,4190$ 으로 나타나고 KOSPI지 수 데이터를 4 개의 구간으로 나눈다고 할 때 PL-C 세 개의 싸이클 다음에 PL로 마감됨을 볼 수 있다. 분산값을 보면 구조변화점 위치 $t=3170,3470,4190$ 에 대응되는 세 개의 $\mathrm{C}$ 에서 변동성이 크게 증가함 을 알 수 있다. 특히 두 번째 $\mathrm{C}(2008$ 년 미국 서브프라임사태로 촉발된 금융위기)에서 변동성이 매우 커 졌음을 알 수 있다. RR, DET, $L, \mathrm{ENTR}, \mathrm{LAM}, \mathrm{TT}$ 에서는 깊은 골짜기를 통하여, RTE에서는 피크를 통하여, $T_{2}$ 에서는 값의 심한 변동을 통하여 세 개의 $\mathrm{C}$ 를 확인할 수 있다. Figure 3.2 에서 각 그래프 안 의 5 개의 수직선들은 구조변화점 위치 $t=760,1320,3170,3470,4190$ 를 각각 나타낸다. KOSPI지수 데이터를 6 개의 구간으로 나눈다고 할 때는 PL-C 다섯 개의 싸이클 다음에 PL로 마감됨을 볼 수 있다. 구조변화점 위치 $t=760,1320$ 에 대응되는 두 개의 $\mathrm{C}$ 를 더 확인할 수 있다. 그 중의 하나의 $\mathrm{C}$ 가 1997 년 IMF 외환위기로서 2008년 미국 서브프라임사태로 촉발된 금융위기에 비해서는 변동성이 상대적으 로 약함을 알 수 있다. 흥미로운 사실은 $\mathrm{Kim}$ 과 $\mathrm{Kim}$ (2013)의 일별 환율데이터에 대한 시계열 모형 적 합 연구에서는 1997년 IMF 외환위기시의 변동성이 2008년 미국 서브프라임사태로 촉발된 금융위기시 의 변동성보다 훨씬 크게 나타난다는 것이다. 


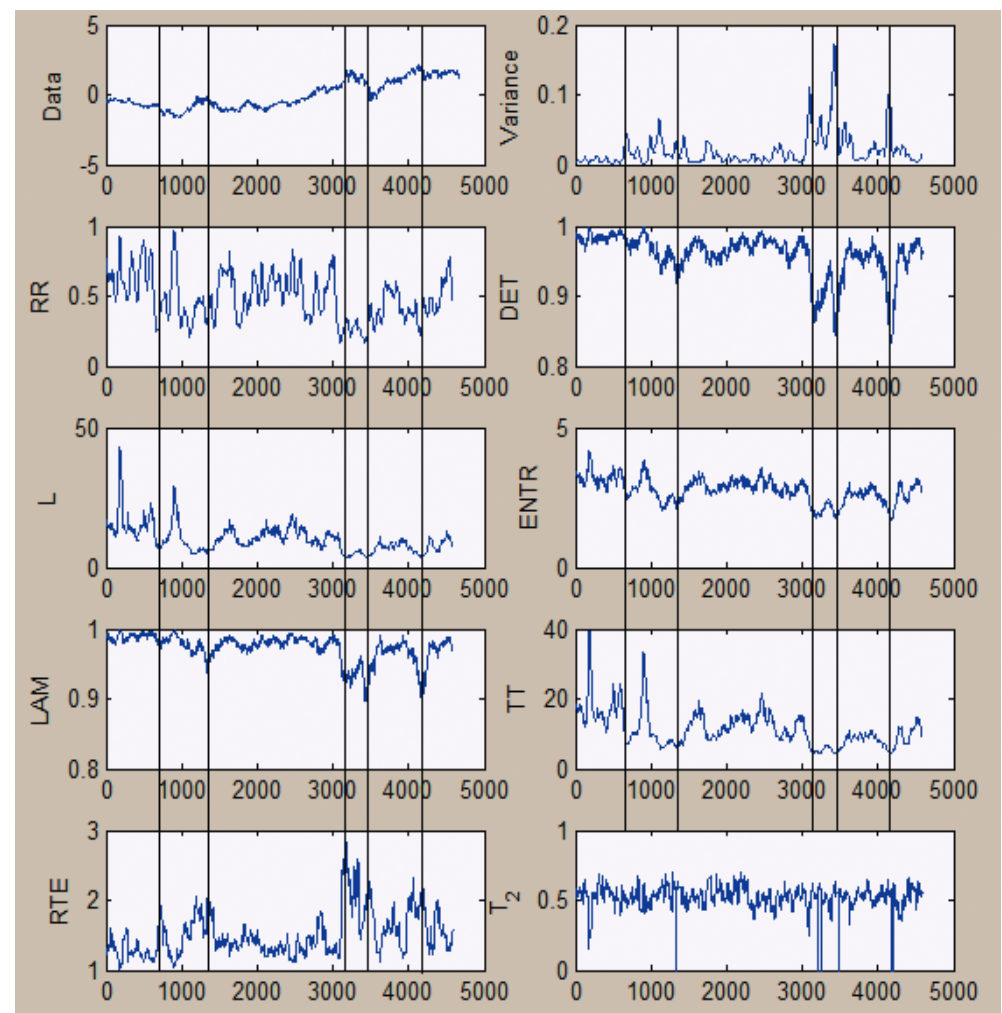

Figure 3.2. RQA Measures for KOSPI data(window size: 100)

참고로 $t=760$ 은 1997 년 11월 29일, $t=1320$ 은 1999년 12 월 23 일, $t=3170$ 은 2007 년 6 월 29 일, $t=3470$ 은 2008 년 9 월 19 일, 그리고 $t=4190$ 은 2011년 8월 3 일에 각각 대응된다.

차분 데이터에 대하여 비분계재현그림, (분계)재현그림, 재현수량화분석 측도값들을 그려보면 각각 Figure 3.3과 Figure 3.4와 같다. Figure 3.3을 통하여 점들이 상당히 골고루 퍼져 있어 차분 데이터는 정 상 시계열이 됨을 확인할 수 있다. 비정상 시계열인 KOSPI지수 데이터에 대한 재현그림과 비교하여 보 면 상당히 다른 패턴을 지니고 있다. 그럼에도 불구하고 재현그림을 통하여 탐색적으로 시계열 데이터 의 구조 변화점을 한 눈에 확인할 수 있게 된다. PL-C 싸이클을 확인할 수 있고 이 싸이클을 통하여 탐 색적으로 시계열 데이터의 구조 변화점을 한 눈에 확인할 수 있다. KOSPI지수 데이터에서처럼 PL-C 세 개의 싸이클 다음에 $\mathrm{PL}$ 로 마감됨을 볼 수 있다. 두 번째 $\mathrm{C}(2008$ 년 미국 서브프라임사태로 촉발된 금융위기)에서 변동성이 매우 커졌음을 알 수 있다. 반면 1997년 IMF 외환위기는 2008년 미국 서브프 라임사태로 촉발된 금융위기에 비해서는 변동성이 상대적으로 약함을 알 수 있다.

\section{4. 삼성전자 주가 데이터에 대한 재현그림을 통한 탐색적 자료분석}

3 절에서 KOSPI지수 데이터에 대한 재현그림을 통한 탐색적 자료분석을 행하여 보았다. 우리는 더 나 아가 우리나라 상장기업의 대표적 주식인 삼성전자 주가 데이터에 대한 재현그림을 통한 탐색적 자료분 석을 행하고 보고 KOSPI지수 데이터에 대한 재현그림을 통한 탐색적 자료분석과 비교하여 볼 필요가 

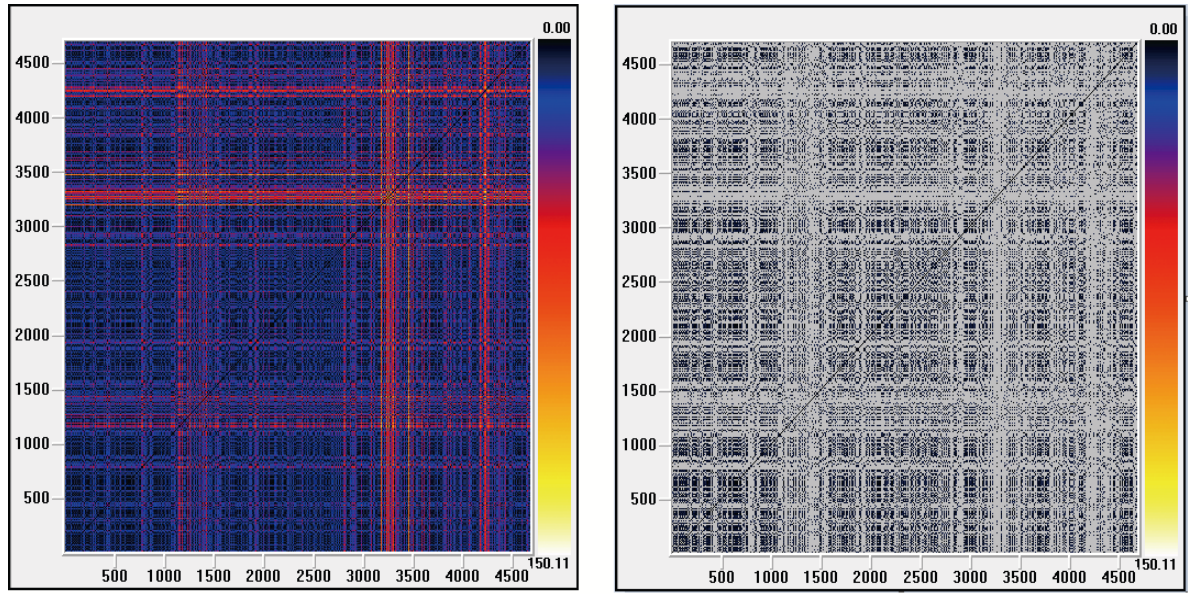

Figure 3.3. Unthresholded recurrence plot and (thresholded) recurrence plot for first differenced KOSPI data
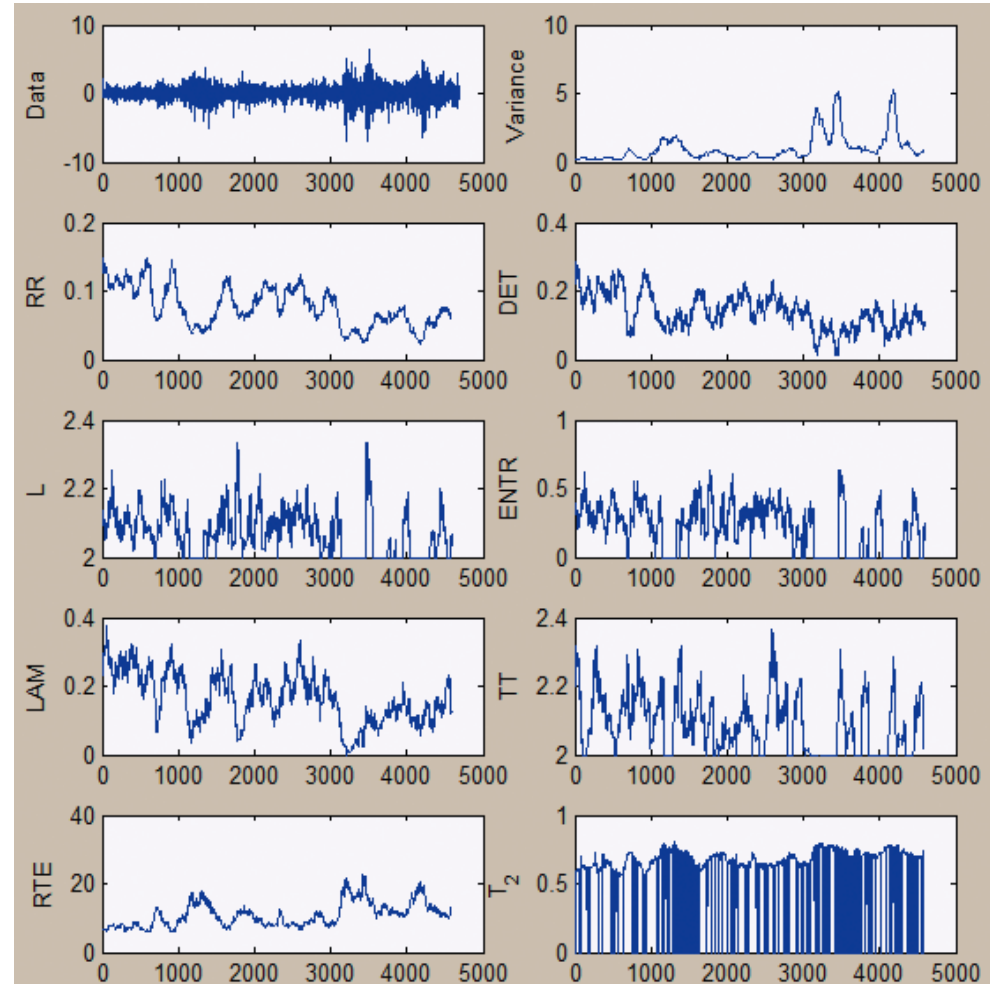

Figure 3.4. RQA Measures for first differenced KOSPI data(window size: 100)

있다. Figure 4.1은 삼성전자 주가 데이터와 차분데이터를 나타낸다. 1차 차분을 통하여 평균이 일정 하여 졌음을 알 수 있고 변동성이 큼을 알 수 있다. 시계열의 정상성 판단을 위하여 $\mathrm{ADF}$ (augmented Dickey-Fuller) 검정을 행하니 삼성전자 주가 데이터에 대한 Dickey-Fuller 검정통계량은 $0.824, p$-값은 

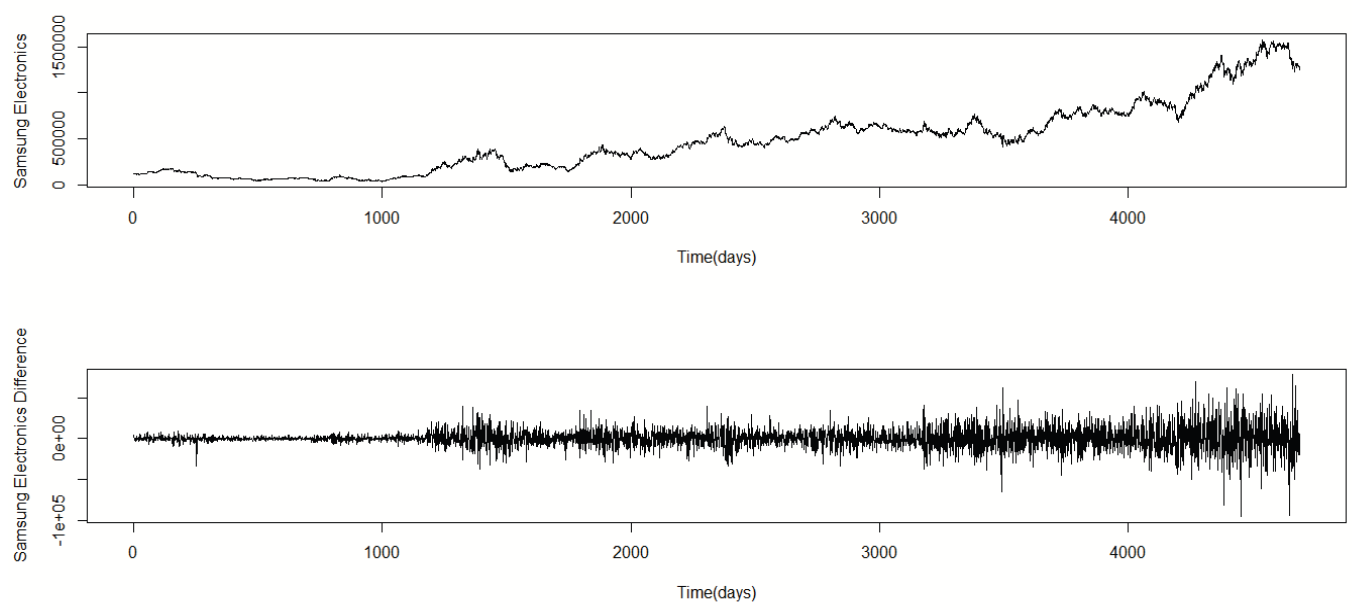

Figure 4.1. Samsung Electronics data and first differenced Samsung Electronics data
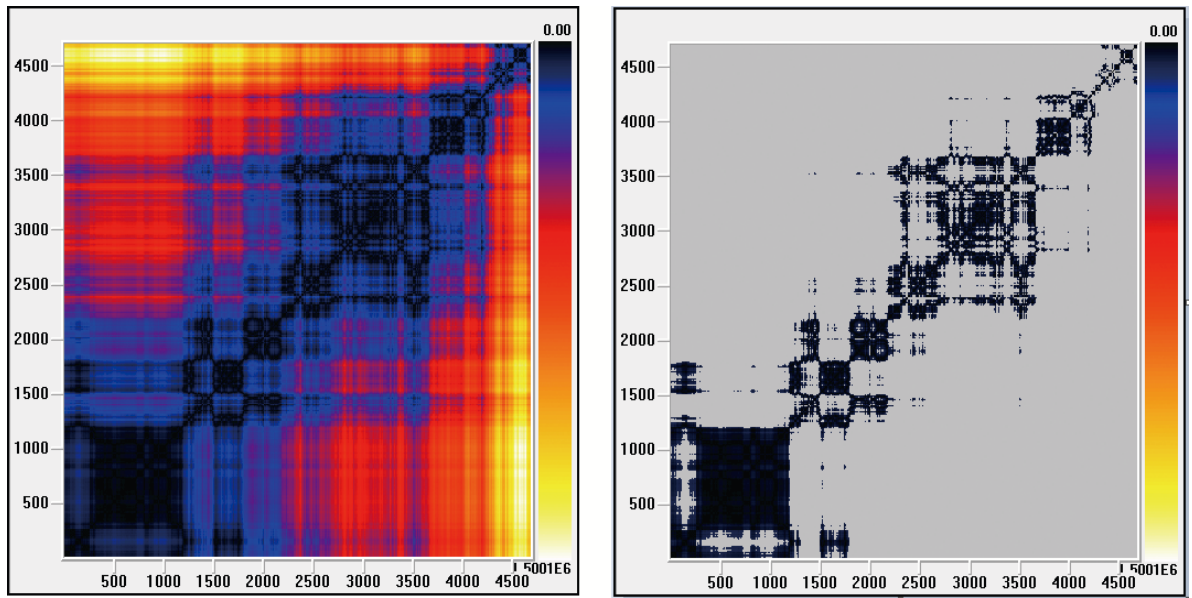

Figure 4.2. Unthresholded recurrence plot and (thresholded) recurrence plot for Samsung Electronics stock price data

0.879로서 삼성전자 주가 데이터가 비정상 시계열임을 알 수 있었고 차분 데이터에 대한 Dickey-Fuller 검정통계량은 $-51.5568, p$-값은 0.01 로서 차분 데이터가 정상 시계열임을 알 수 있었다.

삼성전자 주가 데이터에 대하여 비분계재현그림과 (분계)재현그림을 그리면 Figure 4.2 와 같다. 비분계 재현그림을 보면 칼라색이 골고루 퍼져 있지 않고 다수의 특정 색깔들의 클러스터를 확인할 수 있어 비 정상 시계열임을 확인할 수 있다. Figure 3.1의 KOSPI지수 데이터에 대한 분계재현그림과는 다른 패 턴을 이룬다. (분계)재현그림을 보면 점들이 골고루 퍼져 있지 않고, 특히 좌상, 우하 구석의 빈 공간 및 중간 중간의 빈 공간으로 인하여 비정상 시계열임을 확인할 수 있다.

삼성전자 주가 데이터의 차분 데이터에 대하여 비분계재현그림과 (분계)재현그림을 그려보면 각각 Figure 4.3 과 같다. 점들이 상당히 골고루 퍼져있어 차분 데이터는 정상 시계열이 됨을 확인할 수 있다. 비 정상 시계열인 삼성전자 주가 데이터에 대한 재현그림과 비교해 보면 상당히 다른 패턴을 지니고 있다. 

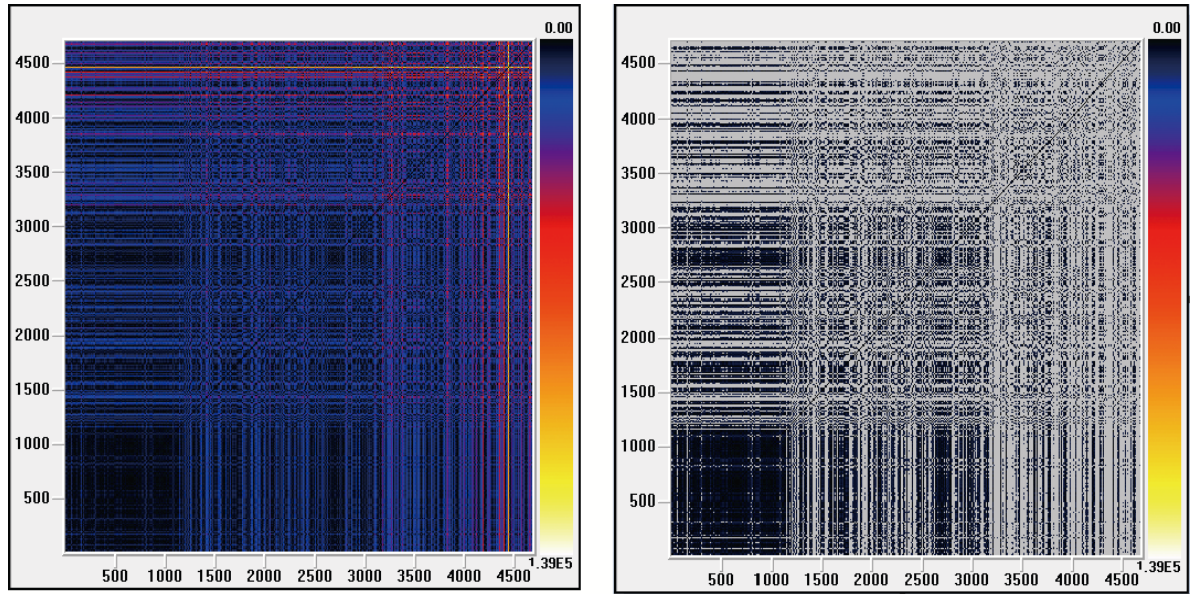

Figure 4.3. Unthresholded recurrence plot and (thresholded) recurrence plot for first differenced Samsung Electronics stock price data
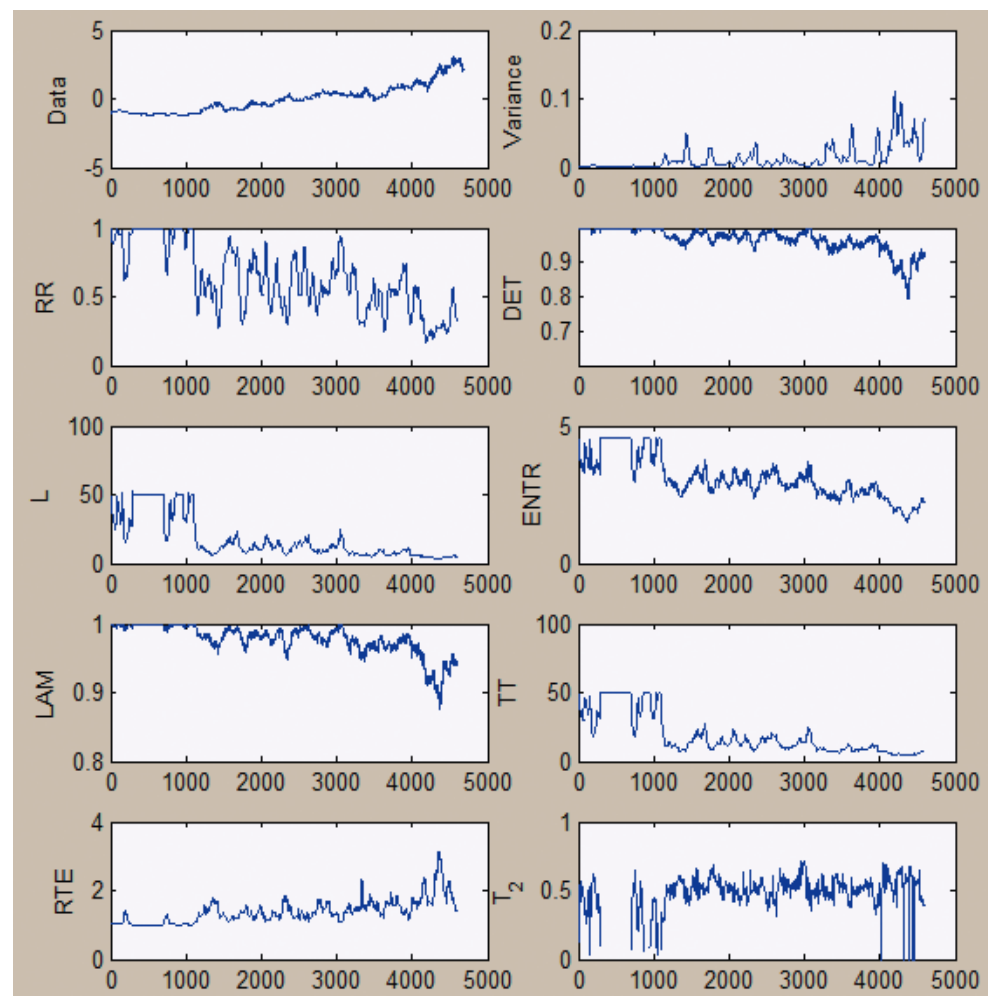

Figure 4.4. RQA Measures for Samsung Electronics stock price data(window size: 100)

Figure 4.4는 삼성전자 주가 데이터에 대하여 창(window)의 크기를 100 으로 하여 창을 1 에서 시작하 여 1씩 증가하여 움직이며 구한 각 종 재현수량화분석을 위한 측도값들을 그린 그림들이다 (대각선 최 
소길이 $l_{\min }$ 과 수직선 최소길이 $v_{\min }$ 는 2 로 하였음.). PL-C 싸이클을 확인할 수 있고 이 싸이클을 통 하여 탐색적으로 시계열 데이터의 구조 변화점을 한 눈에 확인할 수 있다. RR, DET, L, ENTR, LAM, $\mathrm{TT}$ 에서는 깊은 골짜기를 통하여, RTE에서는 피크를 통하여, $T_{2}$ 에서는 값의 심한 변동을 통하여 $\mathrm{C}$ 를 확인할 수 있다. 그런데 삼성전자 데이터의 구조 변화점은 KOSPI 지수의 구조변화점과 비교하면 상이 한 패턴을 이룸을 알 수 있다. 삼성전자 데이터의 구조 변화점은 KOSPI 지수의 구조변화점보다 더 복 잡하게 많을 뿐 만 아니라 KOSPI 지수의 구조변화점에서는 $t=3470(2008$ 년 미국 서브프라임사태로 촉발된 금융위기)에 대응되는 $\mathrm{C}$ 에서 변동성이 제일 크게 증가함을 알 수 있었으나 삼성전자 데이터의 구조 변화점에서는 $t=4190$ 에서 변동성이 제일 크게 증가하였다. 또한 KOSPI 지수의 구조변화점에 서는 $t=4190$ 에서 다시 변동성이 크게 증가한 이 후 상대적으로 안정화되고 있으나 삼성전자 데이터의 구조 변화점에서는 $t=4190$ 이후 최근까지 변동성이 크게 유지되고 있음을 알 수 있다. 삼성전자 데이 터의 구조 변화점에서는 $t=760$ 에 대응되는 $\mathrm{C}(1997$ 년 $\mathrm{IMF}$ 외환위기)가 2008년 미국 서브프라임사태 로 촉발된 금융위기에 비해서는 변동성이 아주 미미한 수준임을 알 수 있다.

\section{5. 결론}

KOSPI 지수와 삼성전자 주가에 대한 재현그림을 통하여 시계열 자료의 구조적 패턴을 확인할 수 있고 이 패턴을 통하여 탐색적으로 시계열 데이터의 구조 변화점을 한 눈에 확인할 수 있음을 보였다. 재현그 림을 그리는 데 통계모형에 대한 가정이 필요가 없다. 또한 재현그림은 수식이 아닌 그림이므로 시계열 자료의 구조적 패턴을 시각적으로 확인할 수 있는 장점이 있다. 그러므로 시계열 자료에 대한 확증적 자 료분석 전에 보조적인 그래픽 탐색적 자료분석 도구로서 재현그림을 활용할 수 있다.

\section{References}

Addo, P. A., Billio, M. and Guegan, D. (2013). Nonlinear dynamics and recurrence plots for detecting financial crisis, North American Journal of Economics and Finance, in press.

Belaire-Franch, J., Contreras, D. and Tordera-Lledo, L. (2002). Assessing nonlinear structures in real exchange rates using recurrence plot strategies, Physica D, 171, 249-264.

Chen, W. (2011). Use of recurrence plot and recurrence quantification analysis in Taiwan unemployment rate time series, Physica A, 390, 1332-1342.

Eckmann, J. P., Kamphorst, S. O. and Ruelle, D. (1987). Recurrence plots of dynamical systems, Europhysics Letters, 5, 973-977.

Guhathakurta, K., Bhattacharya, B. and Chowdhury, A. R. (2010). Using recurrence plot analysis to distinguish between endogenous and exogenous stock market crashes, Physica A, 389, 1874-1882.

Hwang, E. and Shin, D. W. (2013). Stationary bootstrap prediction intervals for GARCH $(p, q)$, Communications of the Korean Statistical Society, 20, 41-52.

Iwanski, J. S. and Bradley, E. (1998). Recurrence plots of experimental data: To embed or not to embed, Chaos, 8, 861-871.

Jang, D. H. (2009). Recurrence plots as an exploratory graphical tool for evaluating randomness, The Korean Journal of Applied Statistics, 22, 1153-1165.

Kim, B. M. and Kim, J. H. (2013). Time series models for daily exchange rare data. The Korean Journal of Applied Statistics, 26, 1-14.

Lee, S. and Noh, J. (2013). An empirical study on explosive volatility test with possibly nonstationary GARCH $(1,1)$ models, Communications of the Korean Statistical Society, 20, 207-215.

Marwan, N., Romano, M. C., Thiel, M. and Kurths, J. (2007). Recurrence plots for the analysis of complex systems, Physics Reports, 438, 237-329.

Matassini, L., Kantz, H., Holyst, J. and Hegger, R. (2002). Optimizing of recurrence plots for noise reduction, Physical Review E, 65, 021102. 
Mindlin, G. M. and Gilmore, R. (1992). Topological analysis and synthesis of chaotic time series, Physica D, 58, 229-242.

Oh, J. and Kim, S. (2013). Value-at-Risk estimation of the KOSPI returns by employing long-memory volatility models, The Korean Journal of Applied Statistics, 26, 163-185.

Park, K., Ko, K. and Beak, J. (2013). An one-factor VaR model for stock portfolio, The Korean Journal of Applied Statistics, 26, 471-481.

Thiel, M., Romano, M. C., Kurths, J., Meucci, R., Allaria, E. and Arecchi, F. T. (2002). Influence of observational noise on the recurrence quantification analysis, Physica D, 171, 138-152.

Zbilut, J. P. and Webber Jr., C. L. (1992). Embeddings and delays as derived from quantification of recurrence plots, Physics Letters A, 171, 199-203.

Zbilut, J. P., Zaldivar-Commenges, J. M., and Strozzi, F. (2002). Recurrence quantification based Liapunov exponents for monitoring divergence in experimental data, Physics Letters A, 297, 173-181. 


\title{
재현그림을 통한 우리나라 주식 자료에 대한 탐색적 자료분석
}

\author{
장대흥 $^{a, 1}$ \\ ${ }^{a}$ 부경대학교 통계학과
}

(2013년 08월 22일 접수, 2013년 09월 27일 수정, 2013년 09월 30일 채택)

요 약

확증적 시계열 자료분석 전의 그래픽 탐색적 자료분석방법으로서 재현그림을 사용할 수 있다. 재현그림을 통하여 시 계열 자료의 구조적 패턴을 확인할 수 있고 이 패턴을 통하여 탐색적으로 시계열 데이터의 구조 변화점을 한 눈에 확 인할 수 있게 된다. 우리나라 주식 자료를 이용하여 재현그림이 시계열 자료를 위한 그래픽 탐색적 자료분석방법으 로서 유용함을 보였다.

주요용어: KOSPI지수, 재현그림, 정상성.

이 논문은 2010학년도 부경대학교의 지원을 받아 수행된 연구임 (PK-2010-037).

${ }^{1}$ (608-737) 부산광역시 남구 용소로 45 , 부경대학교 통계학과, 교수. E-mail: dhjang@pknu.ac.kr. 